\title{
Analysis of Influence of Circular Hole on Stress State of Plate in Pure Bending Condition
}

\author{
Dragan Petrović*, Milan Bižić \\ Faculty of Mechanical and Civil Engineering in Kraljevo, University of Kragujevac, Kraljevo (Serbia)
}

\begin{abstract}
The task of this paper is determining the zone of influence of a circular hole on the stress state of a homogeneous isotropic plate in pure bending condition. For solving the problem, the complex variable method was used which allows the complete analytical determination of the stresses at every point of the plate, and particularly on the contour of the circular hole. The analytical expressions for stresses in the plate of infinite dimensions were the basis for deriving a mathematical formulation which defines the zone as a function of diameter of the hole, inside which there is influence of the hole on the stress state of the plate. Obtained results are verified with FEM using the ANSYS software package whereby the input data for spatial discretization and mesh generation are not previously adjusted but was used a mesh that is generated automatically by the program.
\end{abstract}

Keywords: Circular hole, Stress state, Plate, Pure bending

\section{INTRODUCTION}

The modern way of designing machinery and structures implies facing with very complex requirements referring to accomplishing maximum quality with respect to carrying capacity, economy, reliability, aesthetics, etc. In order to fulfil these requirements, it is necessary to have design and construction based on a complete analysis of deformation and stress states of the observed structure which is as accurate as possible. If the structure is composed of elements like beams, plates or shells, then the equations of the theory of elasticity are used for determination of stress and strain states.

Literature $[1,2]$ present methods for solving some problems of the theory of elasticity, where the solution is reached by integration of differential equations of equilibrium with satisfying the compatibility equations and contour conditions of the analysed problem. In some practical engineering problems, and especially in those which can be simplified with slight approximation, the methods of the theory of elasticity are widely applied and yield sufficiently accurate results. However, if the problem which is being solved differs to a considerable extent from the given theoretical model of the theory of elasticity, it is necessary to make rather rough approximations and therefore the results thus obtained are not sufficiently accurate. A special problem is the design and calculation of mechanical elements of the plate-type weakened with the circular hole. The mechanical elements of the platetype are used very often in design of main parts of railway vehicles such as underframe, bogies, body, etc. These elements also appear in civil engineering machinery, mining and transportation machinery, cranes, air crafts, vessels, supporting structures, and many other applications. Due to the various structural and design requirements at specific places of mentioned machinery and structures the holes are drilled. In addition, the holes may exist in order to optimize design, reduce its own weight, aesthetic reasons, etc. Under the influence of the load at the places around the holes there are the change of stress distribution and occurs a well-known problem of stress concentration. According to the data from engineering practice, those are the machinery or structures with very frequent failures or damages where consequences are often tragic, with casualties and huge material damage. In a lot of cases, the cause is the incomplete and insufficiently precise identification and analysis of stress and strain states.

In the investigation of this phenomenon, a thin plate weakened by a hole and loaded by a certain load is analysed in the largest number of cases [3-11]. The analysis can also cover determination of stress concentration in the thin plate in case with two neighbouring holes or with several holes [12-14]. The problem is reduced to exact determination of stress at certain points of the loaded plate-type element weakened by a circular hole, where there occurs the stress concentration. One of directions of solving this problem whose theoretical postulates are defined in [15-18] is based on the application of complex functions and complex analysis, and it is called the complex variable method.

In accordance with the previous researches and publications, the significant issue for engineering practice is analysis of a homogeneous isotropic plate weakened by a circular hole in pure bending condition. Such a type of problems frequently occurs in a lot of machinery and structures whose design significantly depends on the possibility of exact determination of stress states around the hole. Therefore, determining the zone of influence of a circular hole on the stress state of plate in pure bending condition is the main tasks in this paper.

\section{THEORETICAL FORMULATIONS}

\subsection{Plane stress state}

If a thin plate is loaded by forces which are uniformly distributed along its thickness and act parallel with its bases, then there is a plane stress state. In that case, the plate bases are not loaded so the stress components $\tau_{x z}, \tau_{y z}, \sigma_{z}$ are equal to zero, and the stress state of the plate is determined only by means of the stress components $\sigma_{x}, \sigma_{y}, \tau_{x y}$, which are the functions of the 
coordinates $x$ and $y$. Hence, the plane stress state is defined by the following four group of equations [1].

The first group of equations is made of the equations that connect stresses and volume forces:

$$
\begin{aligned}
& \frac{\partial \sigma_{x}}{\partial x}+\frac{\partial \tau_{x y}}{\partial y}+X=0 \\
& \frac{\partial \tau_{x y}}{\partial x}+\frac{\partial \sigma_{y}}{\partial y}+Y=0
\end{aligned}
$$

where:

$\sigma_{x}, \sigma_{y}$ - the components of normal stresses

$\tau_{x y}$ - the tangential stress

$X, Y-$ the components of volume forces

The second group of equations is made of the equations which define the relations between stresses and strains:

$$
\begin{gathered}
\sigma_{x}=\lambda \bar{\varepsilon}+2 \mu \frac{\partial u}{\partial x} \\
\sigma_{y}=\lambda \bar{\varepsilon}+2 \mu \frac{\partial v}{\partial y} \\
\tau_{x y}=\mu\left(\frac{\partial u}{\partial y}+\frac{\partial v}{\partial x}\right)
\end{gathered}
$$

where:

$\bar{\varepsilon}$ - the surface strain

$\lambda, \mu-$ the Lamé constants which are:

$\lambda=\frac{v E}{(1-2 v)(1+v)}$ and $\mu=\frac{E}{2(1+v)}$

$E$ - the module of elasticity

$v$ - the Poisson coefficient

$u, v$ - the displacements in the direction of the coordinate axes $x, y$

The third equation is the equation which defines the compatibility conditions:

$$
\frac{\partial^{2} \varepsilon_{x}}{\partial y^{2}}+\frac{\partial^{2} \varepsilon_{y}}{\partial x^{2}}=\frac{\partial^{2} \gamma_{x y}}{\partial x \partial y}
$$

where:

$\varepsilon_{x}, \varepsilon_{y}$ - the components of strain

$\gamma_{x y}=\frac{\partial u}{\partial y}+\frac{\partial v}{\partial x}-$ the sliding component

The fourth group of equations is made of the equations which define the contour conditions:

$$
\begin{aligned}
& X_{n}=l \sigma_{x}+m \tau_{x y} \\
& Y_{n}=l \tau_{x y}+m \sigma_{y}
\end{aligned}
$$

where:

$X_{n}, Y_{n}$ - the components of vectors of external forces $l=\cos (n, x), \quad m=\cos (n, y)-$ the directions cosines $n$ - the external normal to the contour

\subsection{Plane stress state expressed through complex potentials}

Solving the problem of the plane stress state is reduced to finding the stress function which will singlevalued determine stresses and strains, satisfying at the same time the equations (1-4). Determination of stresses in the plate weakened by a circular hole is such a type of problem where it is possible to neglect volume forces. The consequence is that there is always a function $U(x, y)$ through which it is possible to express stresses according to the following expressions [1]:

$$
\begin{aligned}
\sigma_{x} & =\frac{\partial^{2} U(x, y)}{\partial^{2} y} \\
\sigma_{y} & =\frac{\partial^{2} U(x, y)}{\partial^{2} x} \\
\tau_{x y} & =-\frac{\partial^{2} U(x, y)}{\partial x \partial y}
\end{aligned}
$$

Function $U(x, y)$ is called the stress function and it must satisfy the following biharmonic equation:

$$
\frac{\partial^{4} U}{\partial x^{4}}+2 \frac{\partial^{4} U}{\partial x^{2} \partial y^{2}}+\frac{\partial^{4} U}{\partial y^{4}}=0
$$

The stresses $\sigma_{x}, \sigma_{y}$ and $\tau_{x y}$ must be single-valued continuous functions to the derivatives of the second order, and the stress function $U(x, y)$ must have continuous derivatives up to the fourth order, where the derivatives starting from the second order must be single-valued functions in the whole observed area. Solving the equation (6) and determination of the stress function in its real form are very frequently rather complicated and practically impossible for the whole series of problems of determination of the stress state of the loaded machine part. One of the methods of solving this problem is reduced to the transfer to the complex field and solving the problem in a complex form. In that case, the stress function, which is a function of two independent variables $x$ and $y$, is expressed through two functions of one complex variable. The problem of solving one function of two independent variables is thus reduced to the problem of determination of two complex functions of one independent variable. Those complex functions are $\phi(z)$ and $\psi(z)$ and they are called complex potentials. The equations of plane stress state expressed through complex potentials are [15]:

$$
\begin{aligned}
& \sigma_{x}+\sigma_{y}=2[\phi(z)+\bar{\phi}(z)]=4 \operatorname{Re} \phi(z) \\
& \sigma_{y}-\sigma_{x}+2 i \tau_{x y}=2\left[\bar{z} \phi^{\prime}(z)+\psi(z)\right]
\end{aligned}
$$

where:

$R e$ - the real part

$\bar{z}$ - the conjugate complex number

The complex potentials, i.e., the functions $\phi(z)$ and $\psi(z)$ are determined from the conditions defined on the contour of the observed problem.

\section{DETERMINATION OF STRESSES IN THE PLATE BY APPLYING THE COMPLEX VARIABLE METHOD}

For solving the problem of a plate weakened by a circular hole (Fig. 1), conformal mapping of the interior of the unit circle with the radius $\rho=0 \div 1$ is performed on the exterior of the circular hole of the plate with the radius $R$ by means of the following function:

$$
z=\omega(\zeta)=\frac{R}{\zeta}
$$

By separating the real and imaginary parts of the equation (8), the expressions for determination of the coordinates $x$ and $y$ as the functions of the coordinates $\rho$ and $\theta$ are obtained: 


$$
\begin{aligned}
& x=\frac{R}{\rho} \cdot \cos \theta \\
& y=-\frac{R}{\rho} \cdot \sin \theta
\end{aligned}
$$

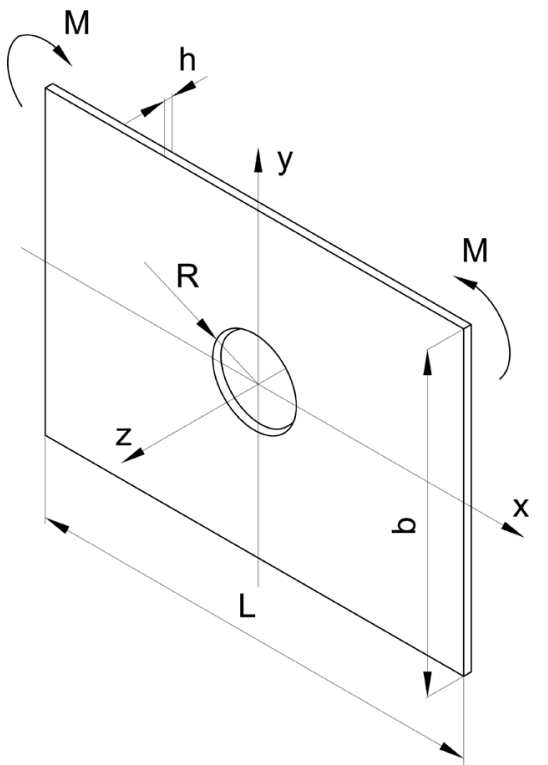

Figure 1. The homogeneous isotropic plate weakened by a circular hole and loaded in pure bending

The relations between the ratios of stresses in Descartes and polar coordinates are:

$$
\begin{aligned}
& \sigma_{\rho}+\sigma_{\theta}=\sigma_{x}+\sigma_{y} \\
& \sigma_{\theta}-\sigma_{\rho}+2 \cdot i \cdot \tau_{\rho \theta}=e^{2 i \alpha}\left(\sigma_{y}-\sigma_{x}+2 \cdot i \cdot \tau_{x y}\right)
\end{aligned}
$$

where:

$\sigma_{\rho}-$ the normal component of the stress on the curve $\rho=$ const.

$\sigma_{\theta}-$ the normal component of the stress on the curve $\theta=$ const.

$\tau_{\rho \theta}$ - the tangential component of the stress on both curves

The stresses expressed in the polar coordinate system through complex potentials in the new mapped zone are defined by the expressions:

$$
\begin{aligned}
& \sigma_{\rho}+\sigma_{\theta}=4 \operatorname{Re} \phi(z) \\
& \sigma_{\theta}-\sigma_{\rho}+2 i \tau_{\rho \theta}=\frac{2 \zeta^{2}}{\rho^{2} \bar{\omega}^{\prime}(\zeta)}\left[\bar{\omega}(\zeta) \phi^{\prime}(\zeta)+\omega^{\prime}(\zeta) \psi(\zeta)\right]
\end{aligned}
$$

The complex potentials for the plate from Fig. 1 are determined according to the expressions:

$$
\begin{aligned}
& \phi(\zeta)=i \cdot A\left(\frac{1}{\zeta^{2}}-\zeta^{2}\right) \\
& \psi(\zeta)=i \cdot A\left(\zeta^{2}-2 \zeta^{4}-\frac{1}{\zeta^{2}}\right)
\end{aligned}
$$

The constant $A$ depends on the geometry of the plate and loads, and it is determined according to the expression:

$$
A=\frac{M \cdot R^{2}}{8 \cdot I_{z}}
$$

The expressions for determination of stresses are thus obtained:

$$
\begin{aligned}
& \sigma_{\theta}=\frac{M R \rho^{2}}{2 I_{z}}\left[\left(\frac{3}{2 \rho^{3}}+\frac{1}{2 \rho}\right) \sin \theta+\left(\frac{1}{2 \rho}-2 \rho^{3}-\frac{1}{2 \rho^{3}}\right) \sin 3 \theta\right] \\
& \sigma_{\rho}=\frac{M R \rho^{2}}{2 I_{z}}\left[\left(\frac{1}{2 \rho^{3}}-\frac{1}{2 \rho}\right) \sin \theta+\left(2 \rho^{3}+\frac{1}{2 \rho^{3}}-\frac{5 \rho}{2}\right) \sin 3 \theta\right] \\
& \tau_{\rho \theta}=-\frac{M R \rho^{2}}{4 I_{z}}\left[\left(\frac{\rho}{2}-\frac{1}{2 \rho^{3}}\right) \cos \theta+\left(\frac{3}{2} \rho-2 \rho^{3}+\frac{1}{2 \rho^{3}}\right) \cos 3 \theta\right]
\end{aligned}
$$

On the basis of the expressions (14) and by varying the coordinates $\rho$ and $\theta$ in the mapped area, it is possible to exactly determine the values of stresses at every point of the plate weakened by a circular hole. It is important to note that previously given expressions are established for plate of infinite dimensions. In accordance with the application of the given expressions on the concrete examples, the plates with finite dimensions are observed. In this part of the paper, concrete values of stresses in the section along the axes $x$ and $y$ as well as those on the contour of the circular hole for the plate P1 whose dimensions are $b=8 \mathrm{~cm} ; L=14 \mathrm{~cm} ; h=0,5 \mathrm{~cm} ; R=1 \mathrm{~cm}$ and which is loaded by the bending moment $M=10 \mathrm{kNcm}$, are determined. The values of the main stresses $\sigma_{l}$ and $\sigma_{2}$ are determined when the calculated values of stresses $\sigma_{\rho}, \sigma_{\theta}$, and $\tau_{\rho \theta}$ are replaced in the following expressions:

$$
\begin{aligned}
& \sigma_{1}=\frac{\sigma_{\rho}+\sigma_{\theta}}{2}+\sqrt{\left(\frac{\sigma_{\rho}-\sigma_{\theta}}{2}\right)^{2}+\tau_{\rho \theta}^{2}} \\
& \sigma_{2}=\frac{\sigma_{\rho}+\sigma_{\theta}}{2}-\sqrt{\left(\frac{\sigma_{\rho}-\sigma_{\theta}}{2}\right)^{2}+\tau_{\rho \theta}^{2}}
\end{aligned}
$$

The stresses $\sigma_{x}$ and $\sigma_{y}$ are determined for the sections which coincide with the $x$ and $y$ axes and with the pitch $\Delta \rho=0,1$. They are defined when the calculated values of stresses determined according to the expressions (14) are replaced in the following expressions:

$$
\begin{aligned}
& \sigma_{x}=\frac{\sigma_{\rho}+\sigma_{\theta}}{2}+\frac{\sigma_{\rho}-\sigma_{\theta}}{2} \cos 2 \theta-\tau_{\rho \theta} \sin 2 \theta \\
& \sigma_{y}=\frac{\sigma_{\rho}+\sigma_{\theta}}{2}-\frac{\sigma_{\rho}-\sigma_{\theta}}{2} \cos 2 \theta+\tau_{\rho \theta} \sin 2 \theta \\
& \tau_{x y}=\frac{\sigma_{\rho}-\sigma_{\theta}}{2} \sin 2 \theta+\tau_{\rho \theta} \cos 2 \theta
\end{aligned}
$$

\section{DETERMINATION OF STRESSES IN THE PLATE BY APPLYING THE FINITE ELEMENT METHOD}

Modelling of the plate P1 weakened by a circular hole whose dimensions and load are identical with the dimensions and load used in the analysis by the complex variable method was performed. The homogeneous isotropic plate was also considered, where the plate material was steel with the module of elasticity $E=21000$ $\mathrm{kN} / \mathrm{cm}^{2}$ and the Poisson coefficient $\mu=0,33$. The calculation was carried out using the ANSYS 12 software, and the finite elements of thin plate type were applied for discretization. The input data for spatial discretization and mesh generation are not previously adjusted but was used a mesh that is generated automatically by the program. 


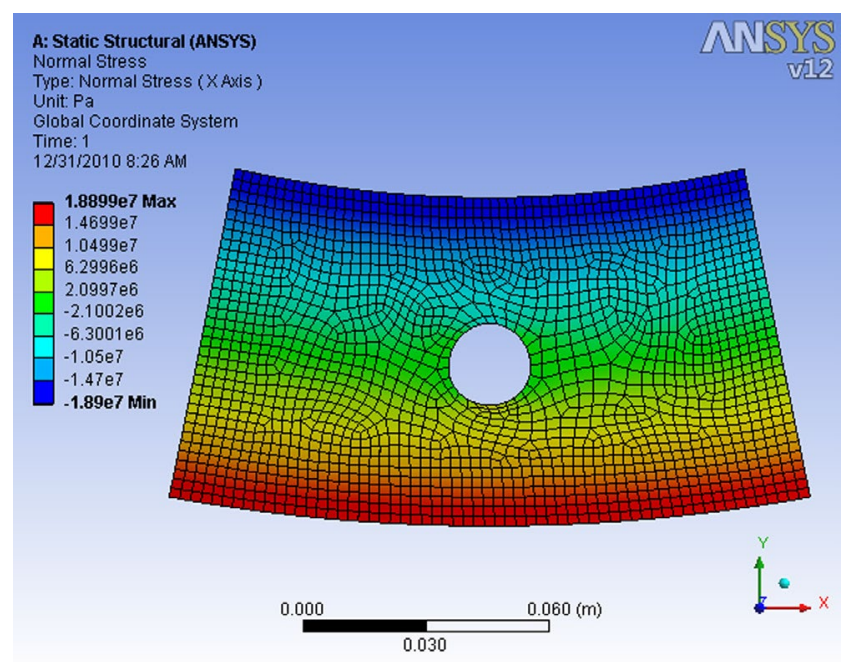

Figure 2. The normal stress $\sigma_{x}$ in the plate P1

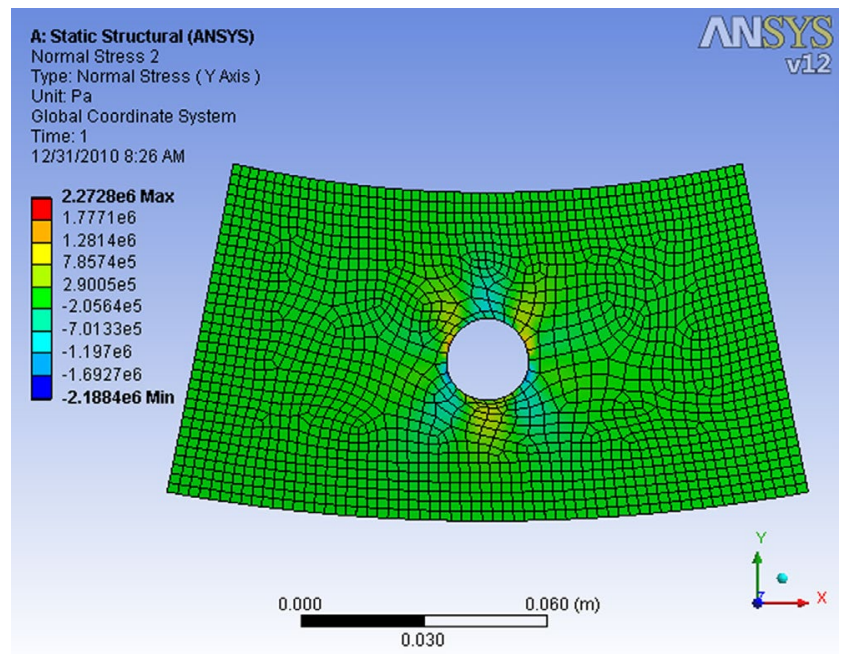

Figure 3. The normal stress $\sigma_{y}$ in the plate P1

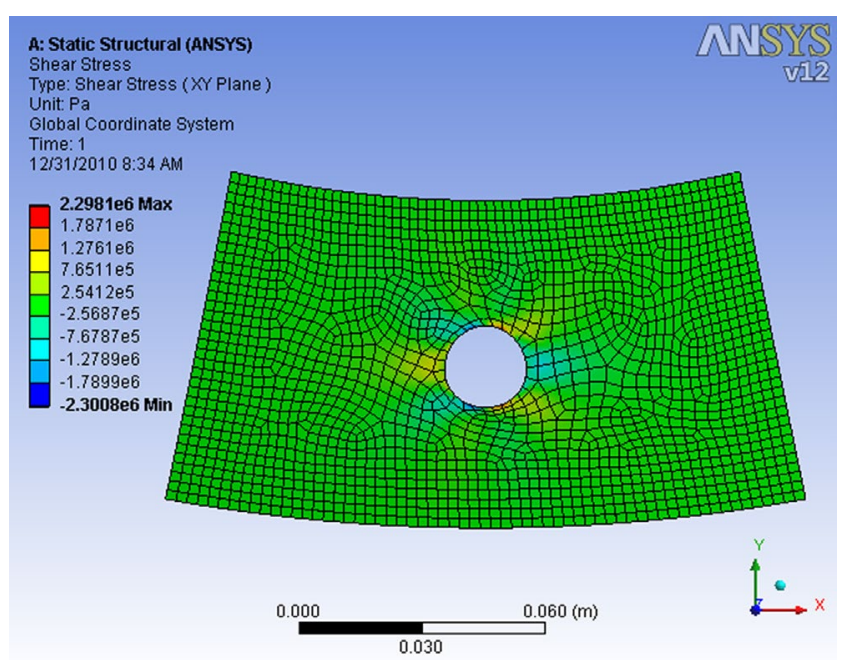

Figure 4. The shear stress $\tau_{x y}$ in the plate P1

For the purpose of comparison with the results obtained by the complex variable method, the values of stresses at the characteristic points of the plate were read and the diagrams of the main stresses on the contour of the hole as well as the diagrams of the stresses $\sigma_{x}, \sigma_{y}$ and $\tau_{x y}$ for the sections which coincide with the $x$ and $y$ axes were created.

\section{COMPARATIVE ANALYSIS OF THE OBTAINED RESULTS}

The following diagrams show the comparative values of changes of stresses for the plate $\mathrm{P} 1$ obtained by means of the complex variable method and the finite element method.

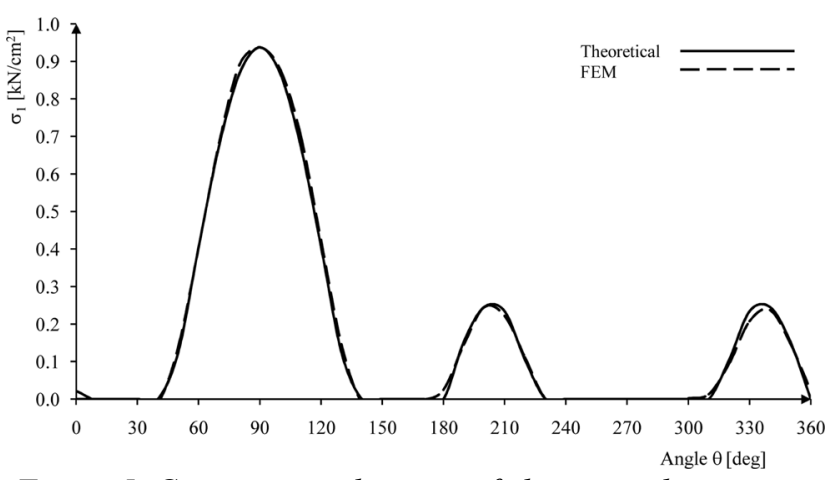

Figure 5. Comparative diagram of change in the stress $\sigma_{1}$ on the contour of the hole of the plate P1

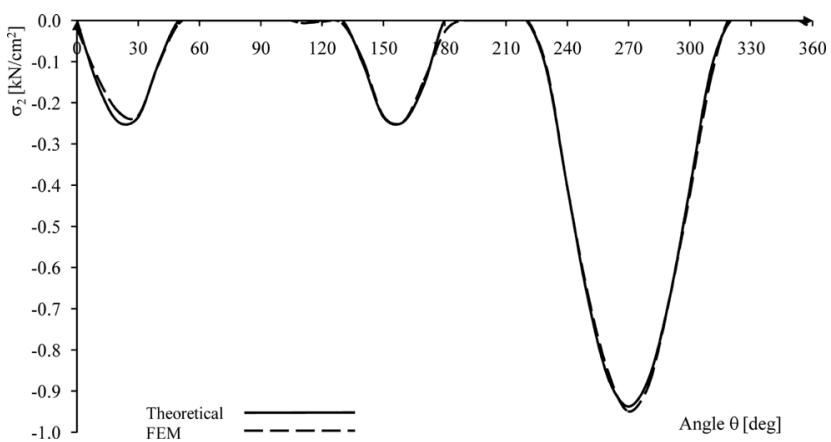

Figure 6. Comparative diagram of change in the stress $\sigma_{2}$ on the contour of the hole of the plate P1

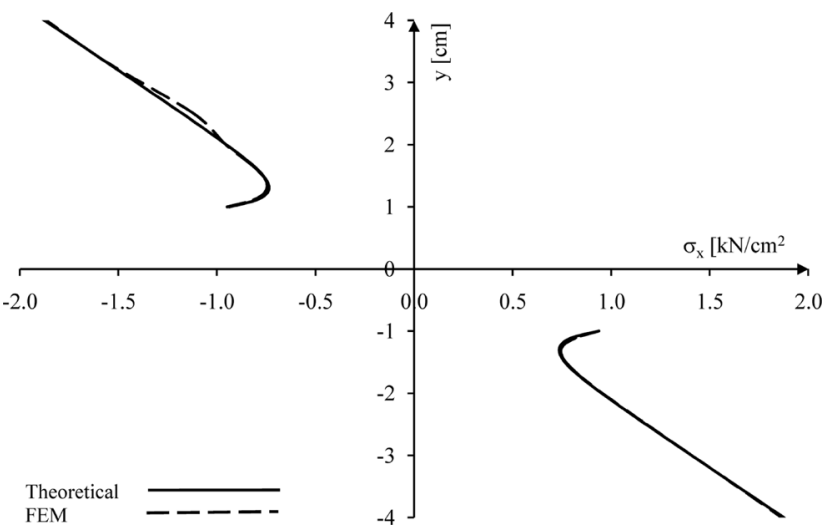

Figure 7. Comparative diagram of change in the stress $\sigma_{x}$ in the section along the $y$ axis of the plate P1

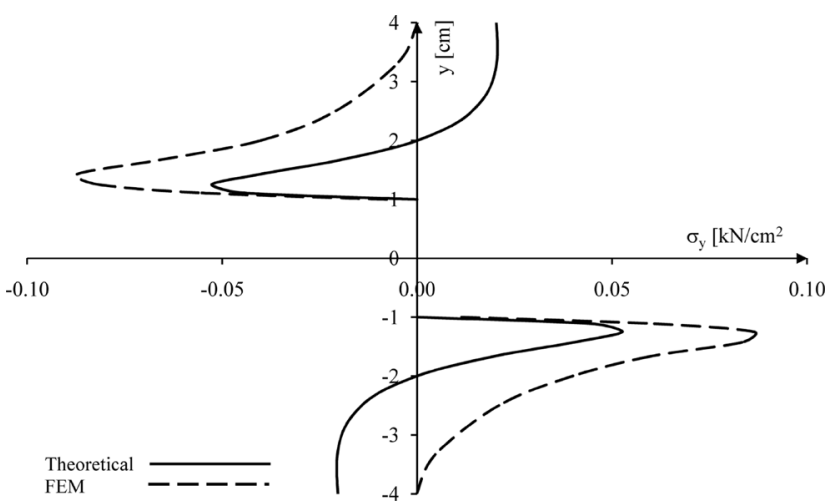

Figure 8. Comparative diagram of change in the stress $\sigma_{y}$ in the section along the $y$ axis of the plate P1 
In the section along the $y$ axis, the tangential stresses $\tau_{x y}$ determined by the application of both methods are equal to zero. Also, in the section along the $x$ axis, the stresses $\sigma_{x}$ and $\sigma_{y}$ determined by the application of both methods are equal to zero and, consequently, only the comparative diagram of the tangential stress $\tau_{x y}$ in the section along the $x$ axis is presented.

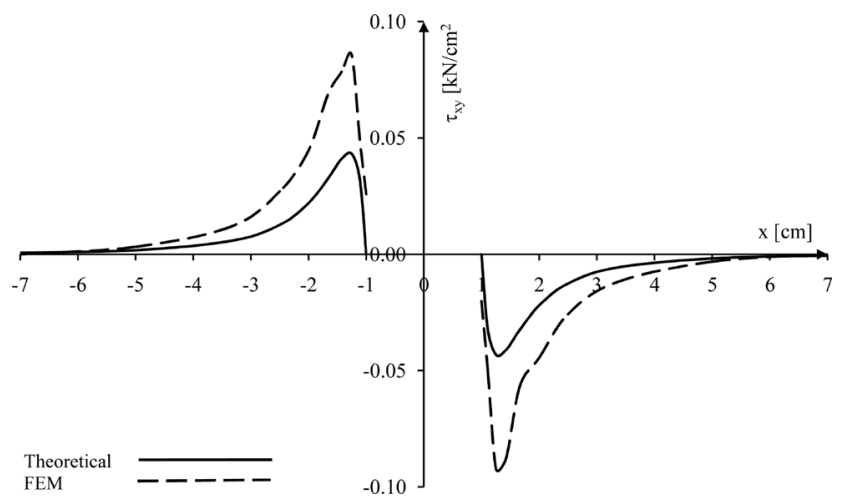

Figure 9. Comparative diagram of change in the stress $\tau_{x y}$ in the section along the $x$ axis of the plate P1

By analysing the obtained results from the comparative diagrams in Figures 5-9 it can be noticed that the stress states are generally identical in both methods, with certain slight deviations which have higher values in small values of stresses. A very important law is also noticed - these deviations are minimum in higher values of stresses, which are the most important for analysis, and at those points of the plate the values of stresses coincide almost perfectly.

\section{DETERMINING THE ZONE OF INFLUENCE}

Based on the previously given analytical expressions for the stresses in the plate of infinite dimensions it is possible to determine the zone of influence of a circular hole on the stress state of plate. The homogeneous isotropic plate P2 with finite dimensions was analysed for that purpose, in variants with and without a hole. It was assumed that in both cases the plate is loaded by the bending moments $M=20 \mathrm{kNcm}$ acting in the plane of the plate and causing pure bending condition. The plate dimensions are: $R=1 \mathrm{~cm} ; h=0,5 \mathrm{~cm} ; b=10 \mathrm{~cm}$; and $L=20 \mathrm{~cm}$. In thus adopted dimensions, the size of the hole is much smaller in relation to the plate dimensions so that the obtained results can be generalized to the case when the hole is in the infinite plate.

The stress in the plate P2 which is not weakened by a hole is determined on the basis of the expression known from the strength of materials:

$$
\sigma_{x, n}=\frac{M}{I_{z}} \cdot y
$$

where: $I_{z}=h \cdot b^{3} / 12-$ the moment of inertia of the cross section of the plate in relation to the axis $z$

At the same time, the stresses $\sigma_{y}$ and $\tau_{x y}$ for the plate $\mathrm{P} 2$ without a hole are equal to zero. The stress in the plate $\mathrm{P} 2$ weakened by a hole is determined according to the expressions (14) and (16). The comparative values of stresses determined according to the previously defined expressions for the plate $\mathrm{P} 2$ are given in the following diagrams.

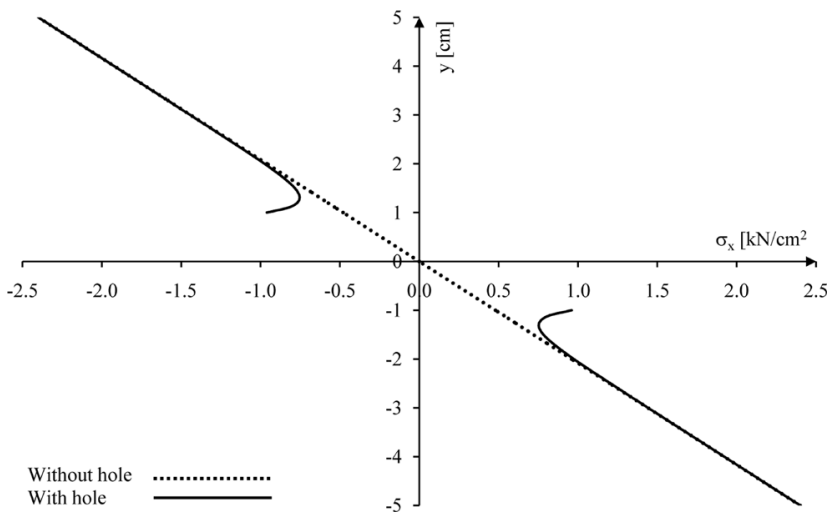

Figure 10. The comparative diagram of the change in the stress $\sigma_{x}$ in the section along the $y$ axis for the plate P2

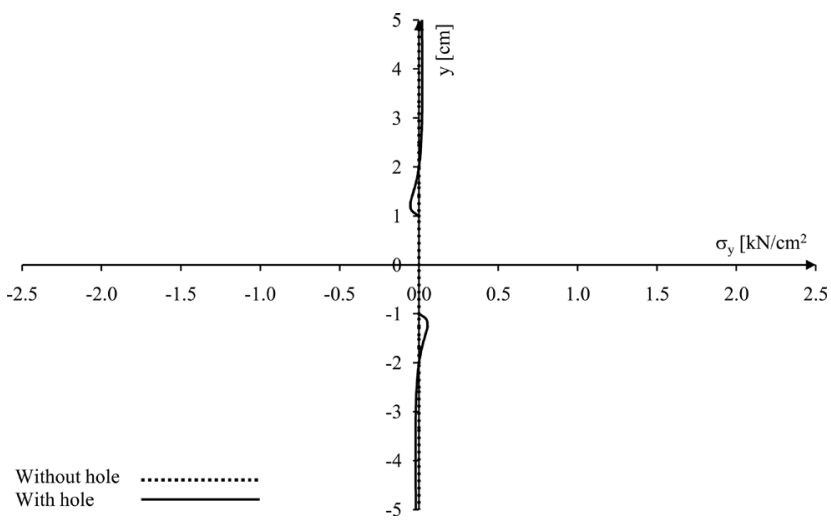

Figure 11. The comparative diagram of the change in the stress $\sigma_{y}$ in the section along the $y$ axis for the plate P2

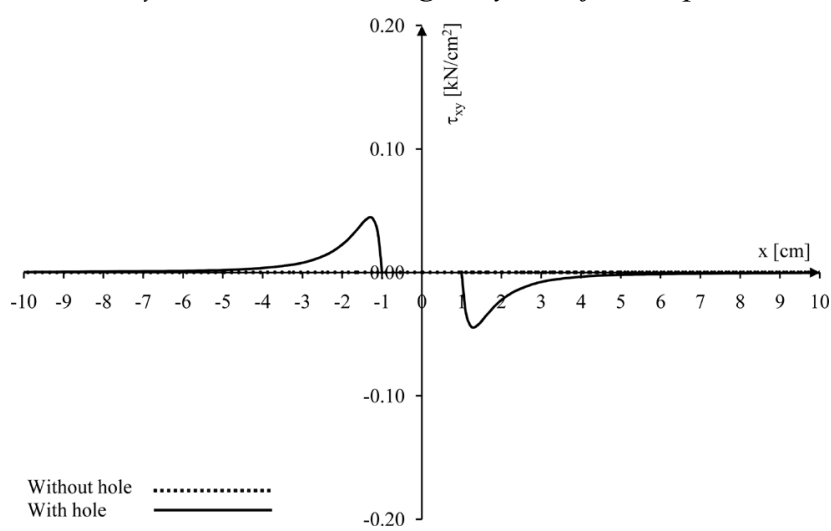

Fig. 12. The comparative diagram of the change in the stress $\tau_{x y}$ in the section along the $x$ axis for the plate P2

The above diagrams show that the influence of the hole on the stress state of the loaded plate declines with the increase of the distance from the hole. That influence completely disappears at a certain distance from the hole and then the stresses become identical to the stresses of the plate which is not weakened by a hole. The diagrams in Figures 10 and 11 show that at the distance $y= \pm 2 R$ the stresses of the plate without a hole and the stresses of the plate with a hole are equal, which means that at this distance the influence of the hole on the stress state of the plate disappears. In Figure 12 it can be noticed that at the distance $x= \pm 5 R$ the stresses of the plate with a hole become equal to the stresses of the plate without a hole, which means that at this distance the influence of the hole on the stress state of the plate disappears. On the basis of this, it can be concluded that the influence of the hole in 
the homogeneous isotropic plate in pure bending condition existed for the following ratios of the radius $R$, the length of the plate $L$ and the height of the plate $b$ (Fig. 1):

$$
\begin{aligned}
& b \leq 4 R \\
& L \leq 10 R
\end{aligned}
$$

The obtained mathematical formulation (18) defines the zone as a function of diameter of the hole, inside which there is influence of the circular hole on the stress state of the plate in pure bending condition (Fig. 13).

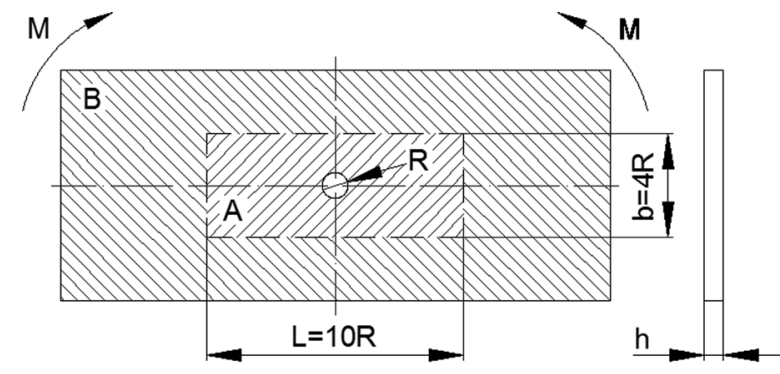

A - The zone with influence

B - The zone without influence

Figure 13. The zone of influence of a circular hole on the stress state of plate in pure bending condition

The established mathematical formulation (18) should bear in mind in analysis of stress state of any plate weakened with a circular hole in pure bending condition. If the dimensions of the considered plate are such that $b \leq 4 R$ and $L \leq 10 R$, the boundaries of the plate are in the zone A, and the hole will have the influence on the stress state of the entire plate. In case the dimensions of the considered plate are such that $b>4 R$ and $L>10 R$, the boundaries of the plate are in the zone B, and the hole will have influence on the stress state of the plate up to the bounds, outside which the hole has no influence. Finally, if one of the dimensions $b$ and $L$ of the considered plate are such that the plate boundaries are both in the zone A and the zone B (for example $b<4 R$ and $L>10 R$ ), in that case the hole will have influence on the plate along the whole given dimension whose boundaries are in the zone A (along the whole height of the plate $b$ ), and along the dimensions whose boundaries are in the zone B (the length of the plate $L$ ), the hole will have influence on the stress state of the plate up to the an bounds, outside which the hole does not have influence any more.

\section{VERIFICATION}

For the purpose of verifying the previous results of the research, the homogeneous isotropic plate P3 weakened by a circular hole, loaded by the bending moment $M=350 \mathrm{kNcm}$ which acts in the plane of the plate and causes pure bending, where the dimensions of that plate are: $R=2 \mathrm{~cm} ; h=0,8 \mathrm{~cm} ; b=18 \mathrm{~cm} ; L=40 \mathrm{~cm}$ was also analysed. The comparative values of the stresses determined according to the expressions (17) for the plate P3 without a hole, and (14) and (16) for the plate P3 weakened by a hole are presented in the following diagrams.

By analysing the results from the diagrams in Figures 14 and 15, it is noticed that also in this case at the distance $y= \pm 2 R$ the stresses of the plate without a hole and the stresses of the plate with a hole are equal, which means that at this distance the influence of the hole on the stress state of the plate disappears. The diagram in Figure 16 shows that in this case, at the distance $x= \pm 5 R$, the stresses of the plate with a hole become equal to the stresses of the plate without a hole, which means that at this distance the influence of the hole on the stress state of the plate disappears. It is confirmed that relations (18) also hold for this plate.

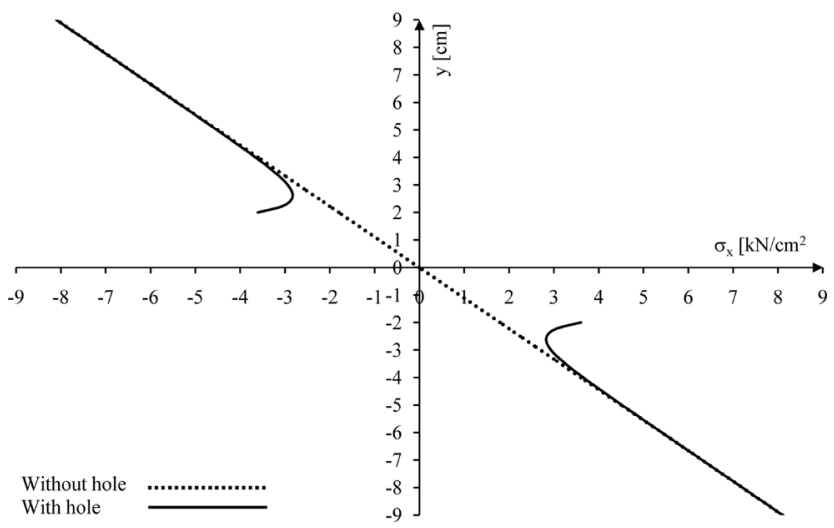

Figure 14. The comparative diagram of the change in the stress $\sigma_{x}$ in the section along the y axis for the plate P3

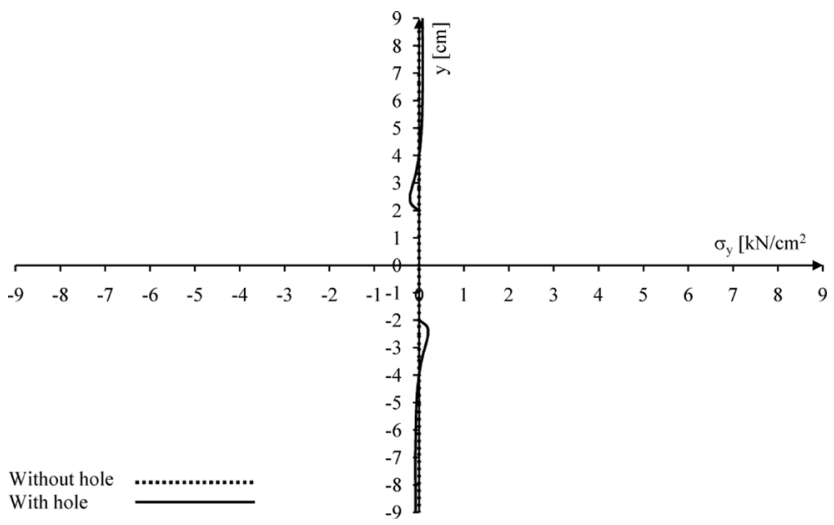

Figure 15. The comparative diagram of the change in the stress $\sigma_{y}$ in the section along the y axis for the plate P3

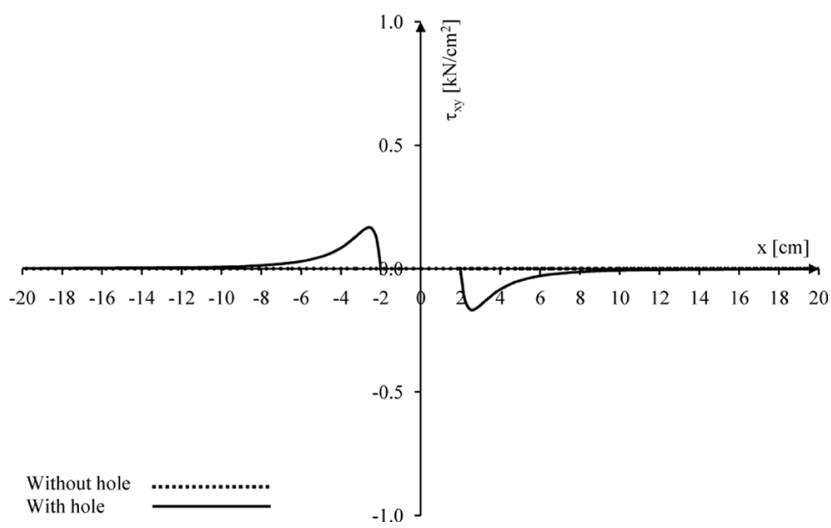

Fig. 16. The comparative diagram of the change in the stress $\tau_{x y}$ in the section along the $x$ axis for the plate P3

\section{CONCLUSION}

Stress states in the homogeneous isotropic plate weakened by a circular hole in pure bending condition determined by the complex variable method and the finite element method are generally identical. There are certain deviations which have higher values at smaller stress values. It is shown that those deviations at higher stress values are minimal and that at those points of the plate the 
stress values almost perfectly coincide according to both methods. On the basis of the research in this paper, it is shown that the complex variable method is very suitable for solving such type of problems. It allows possibility for complete theoretical determination of the stress state at every point of the plate, and especially on the contour of the circular hole. In addition to the identification of stress states, the paper gives a mathematical formulation which defines the zone as a function of diameter of the hole, inside which there is influence of the hole on the stress state of the plate. It is proved that the influence of the hole on the stress state ends for the plate height $b>4 R$ and the plate length $L>10 R$.

The obtained results should bear in mind in analysis of any plate weakened with a circular hole in pure bending condition during the design, construction and calculation of such machinery and structures.

\section{ACKNOWLEDGEMENTS}

The authors wish to express their gratitude to Serbian Ministry of Education, Science and Technological Development for supporting this research (contract no. 451-03-9/2021-14/200108).

\section{REFERENCES}

[1] S. Timoshenko, J.N. Gudier, Theory of elasticity, McGraw-Hill Book Company, New York, (1951)

[2] S. Timoshenko, S. Woinowsky-Kreiger, Theory of plates and shells, McGraw-Hill Book Company, New York, (1959)

[3] N. Troyani, C. Gomes, G. Sterlacci, Theoretical Stress Concentration Factors for Short Rectangular Plates With Centered Circular Holes, Journal of Mechanical Design. Volume 124, Issue 4, 126-128, (2002)

[4] P.S. Chen, R.R Archer, Stress concentration factors due to the bending of a thick plate with circular hole, Archive of Applied Mechanics. Volume 59, Number 6, 401-411, (1989)

[5] X. Yan, B. Liu, A numerical analysis of cracks emanating from a surface elliptical hole in infinite body in tension, Meccanica, Volume 46, Number 2, 263-278, (2011)

[6] K. Chandrashekhara, S.K. Muthanna, Stress analysis of a thick plate having a circular hole under axisymmetric radial load, Archive of Applied Mechanics. Volume 47, Number 1, 1-9, (1978)

[7] Q.Z. Wang, Stress concentration factors for an eccentric circular hole in a finite-width strip or in a semi-infinite plate in tension, The Journal of Strain Analysis for Engineering Design. Volume 39, Number 6, 625-630, (2004)

[8] J.D. Unger, Large Plastic Deformations Accompanying the Growth of an Elliptical Hole in a Thin Plate, Journal of Elasticity. Volume 99, 117-130, (2010)

[9] M. Bižić, D. Petrović, Identifikacija uticaja kružnog otvora na naponsko stanje homogene izotropne jednoosno zategnute ploče, IMK-14 Istraživanje i razvoj, br. 40, 3/2011, 17-22, (2011)
[10] D.Z. Petrović, M.B. Bižić, Mathematical modelling of a plate weakened by a circular hole in pure bending condition, Mechanics Transport Communications, vol. 12, iss. 3/3, pp. VI-45-VI-54, (2014)

[11] M. Bižić, D. Petrović, D. Pančić, Z. Đinović, Mathematical modelling of a disc weakened by an eccentric circular hole, Journal of Theoretical and Applied Mechanics, 50, 4, 1097-1108, (2012)

[12] L. Wu, X. Markenscoff, Singular stress amplification between two holes in tension, Journal of Elasticity. Volume 44, Number 2, 131-144, (1996)

[13] S. Arshadnejad, K. Goshtasbi, J. Aghazadeh, Stress concentration analysis between two neighbouring circular holes under internal pressure of a nonexplosive expansion material, Yerbilimleri. Volume 30, 259-270, (2009)

[14] K.T. Chen, K. Ting, W.S. Yang, Stress analysis of two-dimensional perforated plates using boundary element alternating method, Computers \& Structures. Volume 75, Issue 5, 515-527, (2000)

[15] N.I. Muskhelishvili, Some Basic Problems of the Mathematical Theory of Elasticity, P. Noordhoff, Groningen, (1963)

[16] F.A. Bower, Applied Mechanics of Solids, CRC Press, Boca Raton, (2010)

[17] L. Jian-Ke, Complex Variable Methods in Plane Elasticity, World Scientific Publishing, Sigapore, (1995)

[18] G.N. Savin, Stress concentration around holes, Pergamon press, London, (1961)

\section{Analiza uticaja kružnog otvora na naponsko stanje ploče}

Dragan Petrović*, Milan Bižić

Faculty of Mechanical and Civil Engineering in Kraljevo, University of Kragujevac, Kraljevo (Serbia)

Tema ovog rada je određivanje zone uticaja kružnog otvora na naponsko stanje homogene izotropne ploče u stanju čistog savijanja. Za rě̌avanje problema korišćena je metoda kompleksne promenljive koja omogućava potpuno analitičko određivanje napona $u$ svakoj tački ploče, a naročito na konturi kružnog otvora. $\mathrm{Na}$ osnovu analitičkih izraza za napone u ploči beskonačnih dimenzija izvedena je matematička formulacija koja definiše zonu, kao funkciju prečnika otvora, unutar koje postoji uticaj otvora na naponsko stanje ploče. Dobijeni rezultati su verifikovani rezultatima dobijenim metodom konačnih elemenata pomoću softverskog paketa ANSYS, pri čemu ulazni podaci za prostornu diskretizaciju $i$ generisanje mreže nisu prethodno podešavani, već je korišćena mreža generisana automatski u programu.

Ključne reči: kružni otvor, naponsko stanje, ploča, čisto savijanje 